\title{
Adjuvant radiotherapy and chemotherapy for patients with breast phyllodes tumors: a systematic review and meta-analysis
}

\author{
Xue Chao ${ }^{1,2 \dagger}$, Kai Chen ${ }^{1,2 \dagger}$, Jiayi Zeng ${ }^{3}$, Zhuofei Bi ${ }^{1,4}$, Mingyan Guo ${ }^{1,5}$, Yi Chen ${ }^{1,2}$, Yandan Yao ${ }^{1,2}$, Wei Wu ${ }^{1,2}$,
} Shi Liang ${ }^{1,2}$ and Yan $\mathrm{Ni}^{1,2^{*}}$

\begin{abstract}
Background: As the efficacy of radiotherapy and chemotherapy for treatment of phyllodes tumors (PTs) remains unclear, this study aimed to review all available data and evaluate the roles of radiotherapy and chemotherapy in PT treatment.

Methods: We performed a comprehensive search of databases, including PubMed, Web of Science and the Cochrane Library. The outcomes of interest included the local recurrence (LR) rate, metastasis rate, disease-free survival rate and overall survival rate.

Results: Seventeen studies enrolling 696 patients were included in this random effect meta-analysis. Subgroup analysis and meta-regression were also conducted to determine study heterogeneity. A pooled local recurrence rate of $8 \%(95 \% \mathrm{Cl}: 1-22 \%)$ was observed with a statistical heterogeneity of $\mathrm{I}^{2}=86.6 \%(p<0.01)$ for radiotherapy. This was lower than the recurrence rate of $12 \%$ for simple surgical treatment (95\% Cl: 7-18\%). Meta-regression analysis found that surgical margin status was the main source of heterogeneity $(p=0.04)$. The metastasis rate of 4\% (95\% Cl: 0-11\%) for patients receiving radiotherapy without significant heterogeneity was also lower than the rate for the simple surgery group $(8,95 \% \mathrm{Cl}: 3-15 \%)$. The available data for chemotherapy were too limited to support meta-analysis. Accordingly, we offer a pure review of these data.
\end{abstract}

Conclusion: Our findings suggest that radiotherapy is effective in achieving local disease control and preventing metastasis.

Keywords: Phyllodes tumors, Radiotherapy, Chemotherapy, Meta-analysis

\section{Background}

Phyllodes tumors (PTs) of the breast are typically large, rapidly growing tumors that account for up to $1 \%$ of all breast neoplasms [1]. The World Health Organization (WHO) classifies phyllodes tumors into three histologic subtypes: benign, borderline, and malignant, based on stromal cellularity, stromal cell mitotic activity, stromal

\footnotetext{
*Correspondence: nieyan1010@163.com

${ }^{\dagger}$ Xue Chao and Kai Chen contributed equally to this work.

${ }^{1}$ Guangdong Provincial Key Laboratory of Malignant Tumor Epigenetics and Gene Regulation, Sun Yat-Sen Memorial Hospital, Sun Yat-Sen University, 107 Yanjiang West Road, Guangzhou 510120, People's Republic of China

${ }^{2}$ Breast Tumor Center, Sun Yat-Sen Memorial Hospital, Sun Yat-Sen University, 107 Yanjiang West Road, Guangzhou 510120, People's Republic of China Full list of author information is available at the end of the article
}

nuclear atypia, stromal overgrowth and type of borders (infiltrating or pushing) [2-4].

Although many phyllodes tumors tend to behave in a benign manner, the clinical outcomes of phyllodes tumors are hard to predict because of relatively high recurrence rates and occasional distant metastases. The current approach to preventing local relapse and metastasis is surgical resection with wide margins. However, even with wide surgical resection, the local recurrence rate remains as high as 8 to $36 \%$ [5]. Furthermore, recurrent phyllodes tumors can progress toward more malignant phenotypes [6], in which metastases have been estimated to occur in up to $25 \%$ of patients [7].

Despite these data, no well-established adjuvant therapy applies to high grade phyllodes tumors, which is

(C) The Author(s). 2019 Open Access This article is distributed under the terms of the Creative Commons Attribution 4.0 International License (http://creativecommons.org/licenses/by/4.0/), which permits unrestricted use, distribution, and 
partly due to the controversial roles of adjuvant radiotherapy and chemotherapyl [8]. The use of radiotherapy lacks sufficient prospective study data regarding borderline and malignant PT [9], while the adoption of chemotherapy is yet to solve the rarity of disease presentation [10]. Furthermore, no randomized clinical trials of chemotherapy and/or radiation therapy have been published.

To help address this problem, we performed a literature review and meta-analysis to evaluate the roles of radiotherapy and chemotherapy in $\mathrm{PT}$ treatment.

\section{Methods}

\section{Search strategy}

We performed a comprehensive search of databases, including PubMed, Web of Science, Embase and the Cochrane Library, from 1985 to Feb 1, 2019. The following $\mathrm{MeSH}$ terms and their combinations were searched: (breast tumor/ sarcoma/ neoplasm) and (phyllodes or phyllode) and (radiotherapy/ chemotherapy).

\section{Inclusion and exclusion criteria}

Articles concerning radiotherapy and chemotherapy as adjuvant therapy in women with breast phyllodes tumors were included, regardless of prospective or retrospective ones. However, case reports were excluded. So were studies without the outcomes of interest, such as local recurrence, survival and distant metastasis.

\section{Data extraction}

Data were extracted independently by two of the authors (N.Y. and C.X). Consensus was reached between the two authors if there was a discrepancy among the collected data. For each included study, the following information was collected: author, year of publication, country, months of follow-up, number of total cases and patients treated with adjuvant therapy, surgery type and percentage, type and details of adjuvant therapy, age, tumor size, histological type, margins, number of local recurrences, number of metastases, number of patients surviving disease-free and number of overall survivors. A quality assessment of the included studies was also performed based on the tool for case series studies provided by U.S. Department of Health \& Human Services (https://www.nhlbi.nih.gov/ health-topics/study-quality-assessment-tools). Per study, there were many aspects of study design that required termwise evaluation, including objective of the study, cases definition, subjects, interventions, outcome measures, follow-up, statistical methods and results. Quality reviewers could select "yes," "no," or "cannot determine/not reported/not applicable" in response to each item on the tool. For each item where "no" was selected, reviewers were instructed to consider the potential risk of bias that could be introduced by that flaw in the study design or implementation. Cannot determine and not reported were also noted as representing potential flaws. The procedure was done independently by two reviewerss (X.C and K.C.). A review grade (good, fair or poor) was allocated to each study. A "good" study has the least risk of bias, and results are considered to be valid. A "fair" study is susceptible to some bias deemed not sufficient to invalidate its results. A "poor" rating indicates significant risk of bias.

\section{Meta-analysis}

As the data included in our study were all either $<0.2$ or $>$ 0.8 , these data do not follow a normal distribution, and therefore continuous outcome data could not be carried out. The Free-Tukey double arcsine transformation transformed the data to follow a normal distribution, which then could be used for meta-analysis. Once the meta-analysis is done, the output data were back-transformed and therefore through this process we can compare the data obtained via meta-analysis with original data [11]. Separate analysis was performed based on the transformed proportions using random models. All data were back-transformed to determine the rate and 95\% confidence interval (CI). Statistical heterogeneity among studies was assessed using $\mathrm{Q}$ and $\mathrm{I}^{2}$ statistics. For the $\mathrm{Q}$ statistics, data were heterogeneous if $p$ $<0.1$. The $\mathrm{Q}$ test was used to test for effect size heterogeneity. $\mathrm{I}^{2}$ values of $<25,25-75 \%$ and $>75 \%$ corresponded to low, moderate, and high degrees of heterogeneity, respectively. Sensitivity analysis and meta-regression analyses were conducted to determine the origin of heterogeneity. Meta-regression analysis was achieved by using liner regression models. We also conducted subgroup analyses based on study size, surgery type, age, tumor size, histological type and margins. All statistical analyses were performed by using Stata 13.0 (Stata, College Station, Texas, USA).

\section{Results \\ Search results}

The search strategy identified 337 studies of radiotherapy and 329 studies of chemotherapy. After a thorough review of abstracts and exclusion of duplicated references, 46 studies were treated as candidates. Further examination of the manuscripts led to the inclusion of 17 radiotherapy studies for meta-analysis [3, 9, 12-26]. The literature search flow chart is displayed in Fig. 1. A total of 696 patients were included in the study. The detailed characteristics of the included studies are shown in Table 1. The qualities of the included studies were all rated as good. And the detail of the quality assessment was displayed in Additional file 2: Table S1. Unfortunately, the small number and scale of studies on chemotherapy for PT prevented meta-analysis of the effectiveness of chemotherapy. Nevertheless, studies concerning chemotherapy are listed in Table $2[3,8,10,20,27]$. 


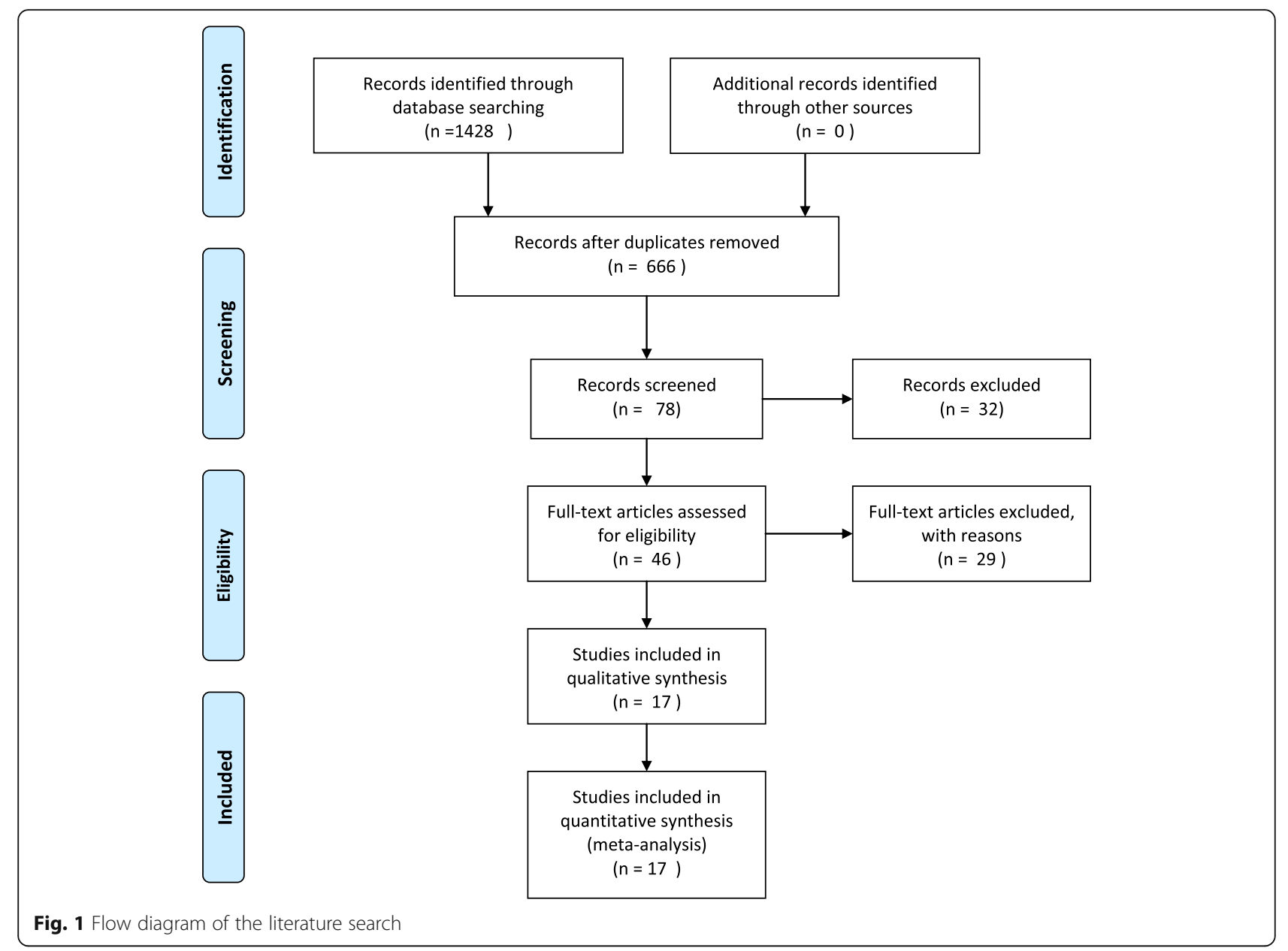

\section{Meta-analysis results} Local recurrence

Analysis of 17 studies revealed that the group that underwent radiotherapy (Fig. 2) plus surgery had a lower local recurrence rate (8\%, 95\% CI: $1-22 \%)$ compared with the pooled local recurrence rate 19\% (95\% CI: $16-32 \%$; test for heterogeneity: $\mathrm{I}^{2}=24.5 \%, p=0.19$ ) for the group that underwent surgery alone, with statistical heterogeneity $\left(\mathrm{I}^{2}=86.6 \%, p<0.01\right)$. Meta-regression analysis revealed that the margin status of surgery accounted for $89.18 \%$ of the heterogeneity $(p=0.04)$. Subgroup analyses were also conducted based on surgery type, age, tumor size, histological type and margins. In general, the subgroup analysis showed that study size, tumor size, age and histological type may also be the causes of heterogeneity. Local recurrence rates of different histological types were also calculated. The results are listed in Table 3.

\section{Distant metastasis}

Twelve studies were combined to reveal a metastasis rate of $4 \%$ (95\% CI: $0-11 \%)$ among patients treated with radiotherapy (Additional file 1: Figure S1). There was no significant statistical heterogeneity in this analysis $\left(\mathrm{I}^{2}=\right.$ $41.2 \%, p=0.07)$. For the group undergoing surgery, the pooled metastasis rate was $8 \%$ (95\% CI: 3-15\%). Subgroup analyses were also conducted based on surgery type, age, tumor size, histological type and margins (Additional file 2: Table S2).

\section{Disease-free survival rate and overall survival rate}

Disease-free survival rate refers to the proportion of patients survives after surgery without any sign or symptom of PTs. Eleven studies were included in the analysis of disease-free survival rate at the median of the follow-up. The total disease-free survival rate was 93\%(95\% CI: 79-100\%) with significant statistical heterogeneity $\left(\mathrm{I}^{2}=76.5 \%, p<0.01\right.$ ) (Additional file 3 : Figure S2). Sensitivity analysis, which was performed by omitting one study at a time and then calculating the pooled disease-free survival rate for the remaining studies, showed that the study by Barth, R.J. [12] had the greatest influence on the pooled rate. After excluding this single study, the disease-free survival rate was $89 \%$ (95\% CI: $\left.72-99 \%, \mathrm{I}^{2}=39.4 \%, p=0.16\right)$. The pooled disease-free survival rate for the surgery group was $70 \%$ (95\% CI: 
Table 1 Characteristics of studies involved in radiotherapy of PT treatment

\begin{tabular}{|c|c|c|c|c|c|c|c|c|c|c|c|c|c|c|c|c|c|c|}
\hline \multirow[t]{2}{*}{ Author } & \multirow[t]{2}{*}{ Year } & \multirow[t]{2}{*}{ Countr } & \multirow[t]{2}{*}{$\begin{array}{l}\text { Follow- } \\
\text { up }\end{array}$} & \multirow[t]{2}{*}{$\begin{array}{l}\text { No. } \\
\text { case }\end{array}$} & \multirow[t]{2}{*}{ Radio } & \multicolumn{2}{|c|}{$\begin{array}{l}\text { Surgery } \\
\text { Type(\%) }\end{array}$} & \multirow[t]{2}{*}{ Age } & \multirow[t]{2}{*}{$\begin{array}{l}\text { Tumor } \\
\text { size }(\mathrm{cm})\end{array}$} & \multicolumn{3}{|c|}{$\begin{array}{l}\text { Histological } \\
\text { Type(\%) }\end{array}$} & \multicolumn{2}{|l|}{ Margin(\%) } & \multirow[t]{2}{*}{ LR } & \multirow[t]{2}{*}{ DFS } & \multirow[t]{2}{*}{ OS } & \multirow[t]{2}{*}{ MS } \\
\hline & & & & & & $\mathrm{BCS}$ & M & & & $\mathrm{Be}$ & Bo & $\mathrm{Ma}$ & $\begin{array}{l}<1 \mathrm{~cm} \\
\text { (positive) }\end{array}$ & $\begin{array}{l}\gg 1 \mathrm{~cm} \\
\text { (negative) }\end{array}$ & & & & \\
\hline Barth & 2009 & Lebano & $56 m$ & 46 & 46 & 100 & 0 & 49 (mean) & 3.7(mean) & 1 & 34.8 & 63.2 & 34.8 & 63.2 & 0 & 46 & 44 & 2 \\
\hline Belkacemi & 2008 & France & 106 m & 443 & 39 & 85.1 & 14.9 & 40 (median) & 3(median) & 64.1 & 18.1 & 17.8 & 15 & 43 & 4 & 26 & 34 & / \\
\hline Chaney & 1998 & USA & $36.5 \mathrm{~m}$ & 8 & 8 & 12.5 & 87.5 & 43 (median) & 10.4(median & 12.5 & 25 & 62.5 & 25 & 75 & 0 & 8 & 8 & / \\
\hline Chaney & 2000 & USA & $47 m$ & 101 & 6 & 47 & 53 & 41 (median) & 4 & 58.4 & 11.8 & 30 & $(0.1)$ & (99.9) & 0 & 6 & 5 & / \\
\hline Chen, W & 2005 & Taiwan & $71 \mathrm{~m}$ & 172 & 2 & 6.4 & 93.6 & 37 (mean) & 5.8(mean) & 76.1 & 6.9 & 17 & (7.5) & (92.5) & 0 & / & 2 & 2 \\
\hline Cheng & 2006 & Taiwan & $30 \mathrm{~m}$ & 81 & 2 & 72.8 & 27.2 & 37(mean) & 7.7 & 72.8 & 7.4 & 19.8 & $(6.2)$ & (93.8) & 0 & / & 2 & 0 \\
\hline Choi & 2018 & Korea & $5 \mathrm{yrs}$ & 362 & 31 & 73.2 & 26.8 & 43(median) & 6 (mean) & / & 64.9 & 35.1 & (10.4) & (89.6) & 1 & 30 & 31 & 0 \\
\hline Cohn-Ce & 1991 & Sweden & $8 y r$ & 77 & 24 & 40.2 & 59.8 & 50 (median) & NA & 51.9 & 0 & 48.1 & / & / & 13 & / & / & 3 \\
\hline Demian & 2016 & Egypt & $52 \mathrm{~m}$ & 35 & 4 & 57 & 43 & 40(median) & 6.8 & 3 & 37 & 60 & (20) & (80) & 0 & 4 & 4 & 0 \\
\hline Gnerlic & 2014 & USA & $53 \mathrm{~m}$ & 3120 & 446 & 56 & 44 & 51.1 (mean) & 4.2(median) & / & / & 100 & (10) & (90) & 132 & / & / & / \\
\hline Guillot & 2011 & France & $\begin{array}{l}12.65 \\
m\end{array}$ & 165 & 8 & 58.7 & 41.3 & 44(median) & 3 & 65.5 & 21.8 & 12.7 & 27.8 & 71.2 & 2 & / & 6 & / \\
\hline Joshi, & 2003 & India & $35 \mathrm{~m}$ & 26 & 4 & 46.2 & 53.8 & 38(median) & 6 (mean) & 65.4 & 11.5 & 23.1 & (15.4) & (84.6) & 0 & 4 & / & 0 \\
\hline Liew, K. W. & 2018 & Sabah & $11 \mathrm{~m}$ & 11 & 6 & 36 & 64 & 45(median) & 10.5(median) & 0 & 0 & 100 & (27) & (73) & 4 & 2 & 6 & 0 \\
\hline Mitus & 2019 & Poland & $12 \mathrm{yrs}$ & 340 & 12 & 100 & 0 & 51 (mean) & 6(mean) & / & 33 & 67 & 100 & 0 & 0 & 12 & 12 & 0 \\
\hline Park, H. J. & 2019 & Korea & $76 m$ & 43 & 43 & 61.4 & 37.6 & 42(median) & 5.8(median) & 0 & 0 & 100 & (9) & (91) & 0 & 37 & 37 & 6 \\
\hline Stranzl & 2004 & Austri & $33.8 \mathrm{~m}$ & 6 & 6 & / & 100 & 53(median) & 7(median) & / & 33 & 67 & 67 & 33 & / & 4 & 5 & 0 \\
\hline Varghese & 2017 & India & $20 \mathrm{~m}$ & 92 & 9 & 51.1 & 48.9 & 43(median) & 10(median) & 60 & 23 & 17 & / & / & 1 & 8 & 9 & 0 \\
\hline
\end{tabular}

$B C S$ breast conserving surgery, $M$ mastectomy, Be benign, Bo borderline, Ma malignant, $L R$ local recurrence, DFS disease-free survival, OS overall survival MS metastasis

40-89\%). The subgroup analysis is shown in Additional file 2: Table S3.

Twelve studies were analyzed to obtain a pooled overall survival rate of $96 \%$ (95\% CI: $89-100 \%$ ) with moderate statistical heterogeneity $\left(\mathrm{I}^{2}=48.7 \%, p=0.02\right)$. The forest plot was displayed in Additional file 4: Figure S3.Subgroup analysis suggested that tumor size, surgery type and especially histological type may be the causes of heterogeneity (Additional file 2: Table S4). We also calculated a combined overall survival rate of $76 \%$ (95\% CI: $17-100 \%)$ for patients who had surgery without any adjuvant therapy.

\section{Discussion}

PTs are divided into three types: benign, borderline and malignant, according to their histological characteristics

Table 2 Characteristics of studies involved in chemotherapy of PT treatment

\begin{tabular}{|c|c|c|c|c|c|c|c|c|c|c|c|c|c|c|c|c|c|c|}
\hline \multirow[t]{2}{*}{ Author } & \multirow[t]{2}{*}{ Year } & \multirow[t]{2}{*}{ Countr } & \multirow[t]{2}{*}{$\begin{array}{l}\text { Follow- } \\
\text { Up }\end{array}$} & \multirow[t]{2}{*}{$\begin{array}{l}\text { Chemo } \\
\text { regime }\end{array}$} & \multirow[t]{2}{*}{$\begin{array}{l}\text { No. } \\
\text { chemoth }\end{array}$} & \multicolumn{2}{|c|}{$\begin{array}{l}\text { Surgery } \\
\text { Type(\%) }\end{array}$} & \multirow[t]{2}{*}{ Age } & \multirow{2}{*}{$\begin{array}{l}\text { Tumor } \\
\text { Size } \\
(\mathrm{cm})\end{array}$} & \multicolumn{3}{|c|}{$\begin{array}{l}\text { Histological } \\
\text { Type(\%) }\end{array}$} & \multicolumn{2}{|l|}{ Margin } & \multirow[t]{2}{*}{ LR } & \multirow[t]{2}{*}{ DFS } & \multirow[t]{2}{*}{ OS } & \multirow[t]{2}{*}{ MS } \\
\hline & & & & & & $\mathrm{BCS}$ & $M$ & & & $\mathrm{Be}$ & Bo & $M$ & $\begin{array}{l}<1 \mathrm{~cm} \\
(\%) \\
\text { (positive) }\end{array}$ & $\begin{array}{l}>1 \mathrm{~cm} \\
(\%) \\
\text { (negative) }\end{array}$ & & & & \\
\hline Chaney, & 2000 & USA & $47 m$ & $\begin{array}{l}\text { doxorubicin- } \\
\text { ifosfamide } \\
\text { ifosfamide } \\
4300 \text { mg }\end{array}$ & 4 & 47 & 53 & 41 (median) & 4 & / & 20 & 80 & $(1)$ & (99) & 0 & 0 & 4 & 4 \\
\hline Guillot, & 2011 & France & $12.65 \mathrm{~m}$ & $\begin{array}{l}\text { Adriamycin } \\
100 \text { mg *6 }\end{array}$ & 9 & 97 & 3 & 44(median) & 3 & / & / & 100 & 28 & 72 & 2 & 6 & 6 & 2 \\
\hline Morales & 2007 & Mexico & $15 \mathrm{~m}$ & $\begin{array}{l}\text { Doxorubicin + } \\
\text { dacarbazine }\end{array}$ & 17 & 23.5 & 76.5 & 42(median) & 13 & / & / & 100 & $(24)$ & (76) & 6 & / & 14 & 10 \\
\hline Wang, F. & 2014 & China & NA & NA & 8 & 61.4 & 38.6 & 49(mean) & 5 & / & / & 100 & NA & NA & / & 5 & 6 & / \\
\hline
\end{tabular}




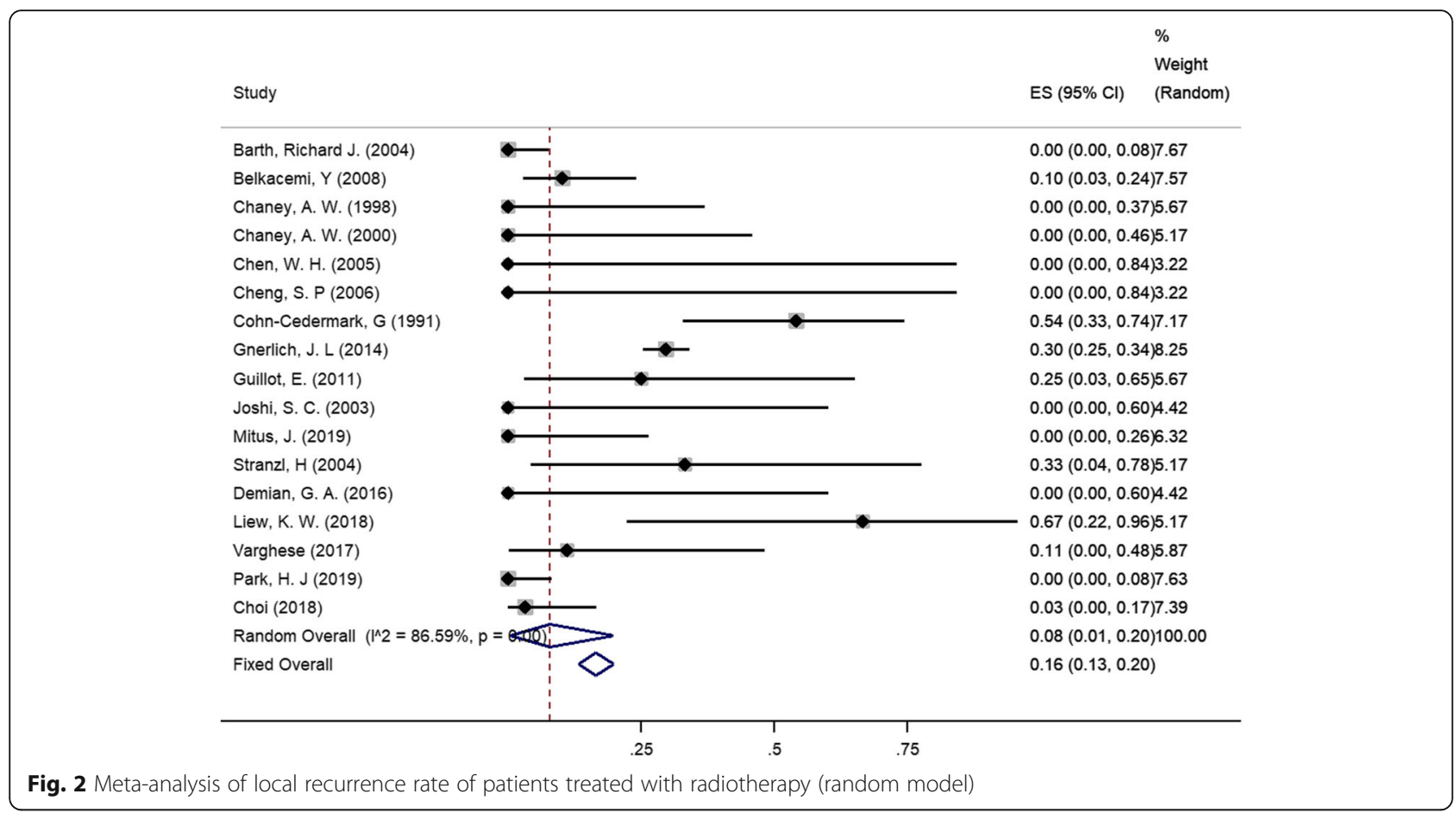

[3]. Surgical treatment, including breast-conserving surgery and mastectomy, are the mainstays of curative treatment of PTs. However, these patients still encounter a fairly high overall recurrence rate of $19.1 \%$ [28] and a $25 \%$ malignant recurrence rate, according to a review involving 5530 patients [28]. Furthermore, malignant and borderline PT had metastasis rates ranging from 22 to $75 \%$ and mortality rates ranging from 23 to $32 \%$ [2932]. These data emphasize the importance of local control and prevention of metastasis.

Currently, the use of adjuvant therapy for PTs remains controversial because of inadequate data from large prospective studies. The absence of these data may be due to the low incidence of PTs and the limited utilization of adjuvant therapy.

Recently, adjuvant radiotherapy has been more frequently utilized. According to a study in the National Cancer Database from the American College of Surgeons' Commission on Cancer involving 3120 patients, adjuvant radiotherapy for PTs in 2008-2009 was used in $19.5 \%$ of cases, more than doubled compared to the rate of $9.5 \%$ in 1998-1999. [18] Data from this large retrospective study suggested that radiotherapy could extend the time to local recurrence and decrease the local recurrence rate, with no significant influence on survival. Another prospective study also discussed the effectiveness of radiotherapy for local disease control [12]. However, scant data has discussed the relationship between radiotherapy and metastasis. The pooled LR rate for patients who underwent both radiotherapy and surgery was (8\%, 95\% CI: $1-22 \%)$. These data were lower than both our calculated LR rate of $19 \%$ (95\% CI: 7-18\%) and the pooled LR rates of borderline (13\%) and malignant (18\%) reported by a meta-analysis [33]. Furthermore, the results of our subgroup analysis suggested that irradiation may be more effective in younger patients $(<45$ years), patients with larger tumors, patients with malignant tumors and patients with wider excision. The meta-regression analysis also confirmed the importance of margin status in local control. These data emphasize the importance of ensuring adequate surgical margins. However, surgery type showed less impact on disease control based on the subgroup analysis. We suggest that for those PTs with high malignancy, radiotherapy should be used as adjuvant therapy without consideration of the surgery type. Our calculated metastasis rate of $4 \%$ (95\% CI: $0-13 \%)$ in patients treated by radiotherapy, compared with a metastasis rate of $8 \%(95 \%$ CI: $3-15 \%)$ in patients receiving only surgical treatment, also suggested that radiotherapy may be effective in the prevention of metastasis. Although our calculated survival data (disease-free survival rate: $93 \%$, overall survival rate: $96 \%$ ) for radiotherapy are higher than those for the surgery group (disease-free survival rate rate: $70 \%$, overall survival rate: $76 \%$ ), they are similar to the data from the Surveillance, Epidemiology, and End Results database (SEER). The estimated 5-, 10-, and 15-year rates of cancer-specific survival for all women were 91,89 , and $89 \%$, respectively [34]. This suggests that radiotherapy may have little effect on prolonging survival. Further subgroup analysis 
Table 3 Sub-group analysis of LR rate of radiotherapy + surgery

\begin{tabular}{|c|c|c|c|c|}
\hline \multirow[t]{2}{*}{ Characteristic } & \multirow{2}{*}{$\begin{array}{l}\text { No. of } \\
\text { studies }\end{array}$} & \multirow{2}{*}{$\begin{array}{l}\text { Recurrence } \\
\text { rate }(95 \% \mathrm{Cl})\end{array}$} & \multicolumn{2}{|c|}{ Heterogeneity } \\
\hline & & & $p$ & $\mathrm{I}^{2}(\%)$ \\
\hline \multicolumn{5}{|l|}{ Study size } \\
\hline$<20$ & 11 & $0.07(0.00-0.21)$ & 0.08 & 40.5 \\
\hline$\geq 20$ & 6 & $0.11(0.00-0.30)$ & $<0.01$ & 94.9 \\
\hline \multicolumn{5}{|l|}{ Follow-up } \\
\hline$<5$ yrs & 11 & $0.10(0.00-0.34)$ & $<0.01$ & 82.9 \\
\hline$\geq 5 \mathrm{yrs}$ & 6 & $0.06(0.00-0.25)$ & $<0.01$ & 87.0 \\
\hline \multicolumn{5}{|l|}{ Surgery type } \\
\hline $\mathrm{BCS} \geq 60 \%$ & 8 & $0.11(0.00-0.31)$ & $<0.01$ & 88.1 \\
\hline BCS < $60 \%$ & 9 & $0.06(0.00-0.20)$ & $<0.01$ & 65.3 \\
\hline \multicolumn{5}{|l|}{ Age } \\
\hline$<45$ & 11 & $0.01(0.00-0.04)$ & 0.36 & 8.6 \\
\hline$\geq 45$ & 6 & $0.22(0.04-0.48)$ & $<0.01$ & 92.6 \\
\hline \multicolumn{5}{|l|}{ Tumor size } \\
\hline$<5 \mathrm{~cm}$ & 5 & $0.18(0.02-0.42)$ & $<0.01$ & 92.3 \\
\hline$\geq 5 \mathrm{~cm}$ & 10 & $0.01(0.00-0.03)$ & 0.38 & 6.3 \\
\hline \multicolumn{5}{|l|}{ Histologic Type } \\
\hline $\mathrm{Bo}+\mathrm{M}$ & 8 & $0.10(0.05-0.28)$ & $<0.01$ & 93.2 \\
\hline Malignant & 9 & $0.06(0.00-0.20)$ & 0.13 & 35.5 \\
\hline \multicolumn{5}{|l|}{ Margin } \\
\hline$>1 \mathrm{~cm} \geq 50 \%$ & 4 & $0.01(0.00-0.15)$ & 0.08 & 55.5 \\
\hline$>1 \mathrm{~cm}<50 \%$ & 3 & $0.08(0.00-0.27)$ & 0.12 & 53.4 \\
\hline Positive $\geq 10 \%$ & 6 & $0.10(0.05-0.27)$ & 0.04 & 57.4 \\
\hline Positive < 10\% & 3 & $0.05(0.00-0.45)$ & $<0.01$ & 95.0 \\
\hline
\end{tabular}

also showed improved survival among patients with cleaner margins.

Our review of the available data shows a negligible role for chemotherapy in the treatment of PTs. Most clinicians avoid chemotherapy as a first-line treatment due to lack of evidence. To date, there has been only one prospective study involving 28 patients, which has showed that chemotherapy has little effect on survival [10]. The sample sizes of other retrospective studies were also too small to prove the efficacy of chemotherapy for PTs treatment. Moreover, PTs with higher histological grades have higher metastatic potential. Few studies discuss the treatment for patients with metastatic PTs. However, the results of these few studies seem promising as nearly half of the patients exhibited partial responses to treatment [20,35].

Our study was the first meta-analysis designed to evaluate the efficacy of radiotherapy in PTs treatment. However, there were some limitations to our study. First, we calculated only recurrence and survival rate data without considering elapsed time. Second, the studies in our meta-analysis were all observational studies, the quality of which may be sub-optimal. In conclusion, the limited incidence of PT remains a challenge for the study of PT.

\section{Conclusions}

In summary, this study indicates that radiotherapy is effective in PTs disease control without prolonging survival. However, the data examined were mostly retrospective and permitted comparative analysis between published treatments, which is a common limitation throughout the literature. Therefore, further studies, particularly prospective studies, are needed to prove the efficacy of adjuvant therapy.

\section{Additional files}

Additional file 1: Figure S1. Meta-analysis of metastasis rate of patients treated with radiotherapy (random model). (TIF $3097 \mathrm{~kb}$ )

Additional file 2: Table S1. Quality assessment of the included studies. Table S2. Subgroup analysis of metastasis rate of radiotherapy. Table S3. Subgroup analysis of disease-free survival rate. Table S4. Subgroup analysis of overall survival rate. (ZIP $73 \mathrm{~kb}$ )

Additional file 3: Figure S2. Meta-analysis of disease-free survival rate of patients treated with radiotherapy (random model). (TIF $1101 \mathrm{~kb}$ )

Additional file 4: Figure S3. Meta-analysis of overall survival rate of patients treated with radiotherapy (random model). (TIF $1054 \mathrm{~kb}$ )

\section{Abbreviations}

Cl: Confidence interval; LR: Local recurrence; PT: Phyllodes tumors

\section{Acknowledgements}

We thank all the women who participated in this study for their willingness to contribute their data.

\section{Funding}

This work was supported by grants from the Natural Science Foundation of China (81502301). Grant KLB09001 from the Key Laboratory of Malignant Tumor Gene Regulation and Target Therapy of Guangdong Higher Education Institutes, SunYat-Sen University and Grant [2013]163 from Key Laboratory of Malignant Tumor Molecular Mechanism and Translational. Medicine of Guangzhou Bureau of Science and Information Technology.

\section{Availability of data and materials}

All eligible studies are listed in our manuscript and reference list as this is a systemic review and meta-analysis.

\section{Authors' contributions}

$X C$ and $Y N$ design this manuscript. YYD, YC and XC performed systematic literature search. XC, KC and JYZ extracted data and performed statistical analysis. SL and JYZ wrote the manuscript. ZFB and MYG helped edited the manuscript. WW and YN reviewed the manuscript. All authors approved the final manuscript.

\section{Ethics approval and consent to participate}

This study involved the use of existing collections of data or records that contain only non-identifiable data. Thus, ethics approval is not needed. Written, informed consent was provided by all participants in each of the studies included in this individual patient meta-analysis.

Consent for publication

Not applicable.

Competing interests

The authors declare that they have no competing interests. 


\section{Publisher's Note}

Springer Nature remains neutral with regard to jurisdictional claims in published maps and institutional affiliations.

\begin{abstract}
Author details
'Guangdong Provincial Key Laboratory of Malignant Tumor Epigenetics and Gene Regulation, Sun Yat-Sen Memorial Hospital, Sun Yat-Sen University, 107 Yanjiang West Road, Guangzhou 510120, People's Republic of China. ${ }^{2}$ Breast Tumor Center, Sun Yat-Sen Memorial Hospital, Sun Yat-Sen University, 107 Yanjiang West Road, Guangzhou 510120, People's Republic of China. ${ }^{3}$ Guangzhou Zhixin High School, 152 Zhixin South Road, Guangzhou 510120, People's Republic of China. ${ }^{4}$ Department of Radiation Oncology, Sun Yat-Sen Memorial Hospital, Sun Yat-Sen University, 107 Yanjiang West Road, Guangzhou 510120, People's Republic of China. ${ }^{5}$ Department of Anesthesiology, Sun Yat-sen Memorial Hospital, Sun Yat-sen University, 107 Yanjiang West Road, Guangzhou 510120, People's Republic of China.
\end{abstract}

Received: 25 October 2018 Accepted: 5 April 2019

Published online: 23 April 2019

\section{References}

1. Pimiento JM, Gadgil PV, Santillan AA, Lee MC, Esposito NN, Kiluk JV, Khakpour N, Hartley TL, Yeh IT, Laronga C. Phyllodes tumors: race-related differences. J Am Coll Surg. 2011;213(4):537-42.

2. Histological typing of breast tumors. Tumori. 1982;68(3):181-98. PMID: 6291202, https://www.ncbi.n/m.nih.gov/pubmed/6291202

3. Guillot E, Couturaud B, Reyal F, Curnier A, Ravinet J, Lae M, Bollet M, Pierga JY, Salmon R, Fitoussi A, et al. Management of phyllodes breast tumors. Breast J. 2011;17(2):129-37.

4. Lakhani SREIO, Schnitt SJ, Tan PH, van de Vijver MJ. World Health Organization Classification of Tumours of the Breast, vol. 4. Lyon: World Health Organization Classification of Tumours; 2012.

5. Barth RJ Jr. Histologic features predict local recurrence after breast conserving therapy of phyllodes tumors. Breast Cancer Res Treat. 1999:57(3):291-5.

6. Shpitz B, Bomstein Y, Sternberg A, Klein E, Tiomkin V, Kaufman A, Groisman G, Bernheim J. Immunoreactivity of p53, Ki-67, and c-erbB-2 in phyllodes tumors of the breast in correlation with clinical and morphologic features. J Surg Oncol. 2002;79(2):86-92.

7. Moffat CJ, Pinder SE, Dixon AR, Elston CW, Blamey RW, Ellis IO. Phyllodes tumours of the breast: a clinicopathological review of thirty-two cases. Histopathology. 1995;27(3):205-18.

8. Chaney AW, Pollack A, McNeese MD, Zagars GK, Pisters PW, Pollock RE, Hunt KK. Primary treatment of cystosarcoma phyllodes of the breast. Cancer. 2000;89(7):1502-11.

9. Stranzl H, Peintinger F, Hackl A. Phyllodes tumor: an unexpected tumor of the breast. A report on six patients. Strahlenther Onkol. 2004;180(3):148-51.

10. Morales-Vasquez F, Gonzalez-Angulo AM, Broglio K, Lopez-Basave HN, Gallardo D, Hortobagyi GN, De La Garza JG. Adjuvant chemotherapy with doxorubicin and dacarbazine has no effect in recurrence-free survival of malignant phyllodes tumors of the breast. Breast J. 2007;13(6):551-6.

11. Freeman MF, Tukey JW. Transformations related to the angular and the square root. Ann Math Stat. 1950;21(4):180.

12. Barth RJ Jr, Wells WA, Mitchell SE, Cole BF. A prospective, multi-institutional study of adjuvant radiotherapy after resection of malignant Phyllodes tumors. Ann Surg Oncol. 2009;16(8):2288-94.

13. Belkacemi Y, Bousquet G, Marsiglia H, Ray-Coquard I, Magne N, Malard Y, Lacroix M, Gutierrez C, Senkus E, Christie D, et al. Phyllodes tumor of the breast. Int J Radiati Oncol Biol Phys. 2008;70(2):492-500.

14. Chaney AW, Pollack A, McNeese MD, Zagars GK. Adjuvant radiotherapy for phyllodes tumor of breast. Radiat Oncol Investig. 1998;6(6):264-7.

15. Chen WH, Cheng SP, Tzen CY, Yang TL, Jeng KS, Liu CL, Liu TP. Surgical treatment of phyllodes tumors of the breast: retrospective review of 172 cases. J Surg Oncol. 2005;91(3):185-94

16. Cheng SP, Chang YC, Liu TP, Lee JJ, Tzen CY, Liu CL. Phyllodes tumor of the breast: the challenge persists. World J Surg. 2006;30(8):1414-21.

17. Cohn-Cedermark G, Rutqvist LE, Rosendahl I, Silfversward C. Prognostic factors in cystosarcoma phyllodes. A clinicopathologic study of 77 patients. Cancer. 1991; 68(9):2017-22.
18. Gnerlich JL, Williams RT, Yao K, Jaskowiak N, Kulkarni SA. Utilization of radiotherapy for malignant Phyllodes tumors: analysis of the National Cancer Data Base, 1998-2009. Ann Surg Oncol. 2014;21(4):1222-30.

19. Joshi SC, Sharma DN, Bahadur AK, Maurya R, Kumar S, Khurana N. Cystosarcoma phyllodes: our institutional experience. Australas Radiol. 2003; 47(4):434-7.

20. Mitus J, Reinfuss M, Mitus JW, Jakubowicz J, Blecharz P, Wysocki WM, Skotnicki P. Malignant Phyllodes tumor of the breast: treatment and prognosis. Breast J. 2014;20(6):639-44.

21. Choi N, Kim K, Shin KH, Kim Y, Moon HG, Park W, Choi DH, Kim SS, Ahn SD, Kim $\mathrm{TH}$, et al. Malignant and borderline phyllodes tumors of the breast: a multicenter study of 362 patients (KROG 16-08). Breast Cancer Res Treat. 2018;171(2):335-44.

22. Demian GA, Fayaz S, El-Sayed Eissa H, Nazmy N, Samir S, George T, El-Sherify M, Abuzalouf S. Phyllodes tumors of the breast: analysis of 35 cases from a single institution. J Egypt Natl Canc Inst. 2016;28(4):243-8.

23. Varghese SS, Sasidharan B, Manipadam MT, Paul MJ, Backianathan S. Radiotherapy in Phyllodes tumour. J Clin Diagn Res. 2017;11(1):XC01-3.

24. Liew KW, Siti Zubaidah S, Doreen L. Malignant phyllodes tumors of the breast: a single institution experience. Med J Malaysia. 2018;73(5):297-300.

25. Mitus JW, Blecharz P, Jakubowicz J, Reinfuss M, Walasek T, Wysocki W. Phyllodes tumors of the breast. The treatment results for 340 patients from a single cancer Centre. Breast. 2018;43:85-90.

26. Park HJ, Ryu HS, Kim K, Shin KH, Han W, Noh DY. Risk factors for recurrence of malignant Phyllodes tumors of the breast. In Vivo. 2019;33(1):263-9.

27. Wang $F$, Jia $Y$, Tong $Z$. Comparison of the clinical and prognostic features of primary breast sarcomas and malignant phyllodes tumor. Jpn J Clin Oncol. 2015:45(2):146-52.

28. Spitaleri G, Toesca A, Botteri E, Bottiglieri L, Rotmensz N, Boselli S, Sangalli C, Catania C, Toffalorio F, Noberasco C, et al. Breast phyllodes tumor: a review of literature and a single center retrospective series analysis. Crit Rev Oncol Hematol. 2013;88(2):427-36.

29. Kapiris I, Nasiri N, A'Hern R, Healy V, Gui GPH. Outcome and predictive factors of local recurrence and distant metastases following primary surgical treatment of high-grade malignant phyllodes tumours of the breast. Eur J Surg Oncol. 2001;27(8):723-30.

30. Asoglu O, Ugurlu MM, Blanchard K, Grant CS, Reynolds C, Cha SS, Donohue $J$ H. Risk factors for recurrence and death after primary surgical treatment of malignant phyllodes tumors. Ann Surg Oncol. 2004;11(11):1011-7.

31. Fou A, Schnabel FR, Hamele-Bena D, Wei XJ, Cheng B, El Tamer M, Klein L, Joseph KA. Long-term outcomes of malignant phyllodes tumors patients: an institutional experience. Am J Surg. 2006;192(4):492-5.

32. Onkendi EO, Jimenez RE, Spears GM, Harmsen WS, Ballman KV, Hieken TJ. Surgical treatment of borderline and malignant Phyllodes tumors: the effect of the extent of resection and tumor characteristics on patient outcome. Ann Surg Oncol. 2014:21(10):3304-9.

33. Lu Y, Chen Y, Zhu L, Cartwright P, Song E, Jacobs L, Chen K. Local recurrence of benign, borderline, and malignant Phyllodes tumors of the breast: a systematic review and meta-analysis. Ann Surg Oncol. 2019. https://doi.org/10.1245/s10434-018-07134-5.

34. Macdonald OK, Lee CM, Tward JD, Chappel CD, Gaffney DK. Malignant phyllodes tumor of the female breast - association of primary therapy with cause-specific survival from the surveillance, epidemiology, and end results (SEER) program. Cancer. 2006;107(9):2127-33.

35. Yonemori K, Shimizu C, Hasegawa T, Matsumoto K, Kouno T, Yamanaka Y, Ando M, Katsumata N, Fujiwara Y. Effectiveness of MAID therapy against metastatic malignant phyllodes tumors and stromal sarcoma of the breast. Breast Care. 2006;1(3):194-7.

Ready to submit your research? Choose BMC and benefit from:

- fast, convenient online submission

- thorough peer review by experienced researchers in your field

- rapid publication on acceptance

- support for research data, including large and complex data types

- gold Open Access which fosters wider collaboration and increased citations

- maximum visibility for your research: over $100 \mathrm{M}$ website views per year

At BMC, research is always in progress.

Learn more biomedcentral.com/submissions 